\title{
Cuarenta años de Allpanchis
}

LA REVISTA ALLPANCHIS CUMPLE CUARENTA AÑos, un verdadero hito para una publicación periódica que con gran perseverancia ha venido ofreciendo, en sus 74 números, estudios que abordan la realidad andina desde diversas disciplinas, corrientes académicas y perspectivas. A lo largo de estos años, la revista ha publicado 691 colaboraciones de unos quinientos autores, con una pluralidad de especialidades — como la Antropología, la Historia, la Sociología o las Ciencias de la Religión- que expresan bien su carácter multidisciplinario. Por todo ello, presentamos en esta edición un número doble conmemorativo.

Las cuatro décadas de nuestra revista coinciden además con cinco décadas de intensa actividad eclesiástica en el sur andino peruano, pues las prelaturas de Ayaviri, Sicuani y Juli fueron creadas contemporáneamente, a fines de la década de 1950. 
La preocupación por un mejor conocimiento de la realidad andina para fines pastorales estuvo en el germen de la creación del Instituto de Pastoral Andina y de nuestra revista en 1969. La idea era generar una plataforma académica seria y rigurosa que colaborase activamente para ampliar el conocimiento del contexto sociocultural de los pobladores de esas tierras. Pasados los años, vemos que este proyecto en buena medida ha sido realizado, no solo por la calidad de los trabajos de investigación publicados sino porque estas contribuciones hoy llegan, por medio de Allpanchis, a los principales centros especializados del mundo.

La importancia que ha tenido el sur andino para un significativo sector de la Iglesia católica está fuera de toda duda. A lo largo de décadas, se ensayaron enfoques pastorales nuevos con particulares visiones sobre la inculturación, la opción por los pobres y la democratización, que sustituyeron tradicionales concepciones y prácticas de evangelización misionera. En una región esencialmente rural que en las décadas de 1950 y 1960 mostraba un culto mayoritariamente católico con importante presencia sincrética de remanentes paganos, sus agentes pastorales aplicaron una concepción radicalmente diversa de acción misionera, que devenía de una reinterpretación aún más radical: una nueva manera de concebir la Iglesia — desde una teología asumida como reflexión crítica sobre la praxis- «más comprometida con los pobres».

Esta nueva visión teológica sobre el modo de abordar la acción pastoral fue impulsada por dos graves preocupaciones en las instituciones eclesiásticas: el problema de la inculturación 
del Evangelio en las comunidades andinas y la imperiosa necesidad de cambiar estructuras injustas que oprimían a crecientes sectores deprimidos y marginados. En el sur andino, la aproximación pastoral estuvo, por ello, confrontada por diversos y complejos procesos sociopolíticos que afectaron directamente la zona, como la reforma agraria, los masivos procesos de migración y la violencia subversiva de Sendero Luminoso, por mencionar algunos. Cabe aún indagar en qué medida los entonces novedosos enfoques pastorales —muy congruentes con la acción de sacerdotes, religiosos y agentes pastorales laicos en el sur andino- tuvieron, efectivamente, el resultado deseado. Como quiera que fuere, parece haber llegado la hora de mirar atrás para ver el camino recorrido, valorar lo que se hizo bien, corregir los errores y aprender de ellos.

Tras cincuenta años de acción pastoral en el sur andino, se hace necesario realizar un balance histórico y sociocultural de los hechos basado en valiosas fuentes documentales directas. Se presenta aquí una periodificación de las etapas pastorales en la prelatura de Ayaviri desde su fundación en 1959 hasta el año 2005. Con base en abundante documentación diocesana, el estudio del sociólogo Alejandro Estenós Loayza y el comunicador social Manuel Ugarte Cornejo identifica cuatro importantes fases en la labor pastoral realizada en casi cincuenta años: 1) tradicionalconservadora (1959-1969), 2) indigenista-culturalista (1970-1974), 3) político-liberacionista (1975-1992) y 4) político-democratizadora (1993-2005). Cada etapa muestra un enfoque pastoral diferente, así como sus implicancias en la acción sociopolítica y religiosa de sus agentes pastorales. 
En conexión con esta investigación, la socióloga Pamela Cabala ofrece en este número un estudio sobre el estado de la religiosidad en Ayaviri en cuatro generaciones. Basándose en casi cuatrocientas encuestas a sus pobladores y separando sus resultados en diversos segmentos etarios, este análisis generacional permite conocer los resultados de los diversos enfoques pastorales en cuanto a creencias y prácticas sacramentales. Se ofrecen, de esta manera, detalles interesantes sobre las prácticas sacramentales y rituales, así como su conexión con las concepciones pastorales aplicadas durante las últimas cinco décadas en este importante poblado del sur andino.

El antropólogo José Sánchez Paredes ofrece en esta edición un artículo que retrata el arduo y constante trabajo que el célebre maestro en los estudios andinos Manuel Marzal S. J. realizó en el IPA. En la medida en que el padre Marzal fue uno de los fundadores e influyó considerablemente en el desarrollo de la entidad editora de esta revista, este artículo honra el rigor y tenacidad de su labor académica, enfocada en la religión andina. Revela también importantes convicciones vinculadas al desarrollo de una teología «comprometida», así como su participación en la concepción y desarrollo ulterior del IPA. Como se señala en el artículo, «La creación del IPA en el Cusco fue uno de los canales importantes de profundización del conocimiento y comprensión de esa religiosidad popular del pueblo campesino» y a este propósito Marzal contribuyó con «estudios esenciales en el propósito de una mayor comprensión de la dinámica y sentido del catolicismo del campesinado andino». 
Otro artículo vinculado con la temática religiosa andina, área de estudio muy acorde con los propósitos fundacionales del IPA, es el que presenta el teólogo e historiador español Luis Martínez Ferrer acerca de las interpretaciones que origina la primera evangelización de América Latina. Según él, son tres las posturas sobre la relación entre la evangelización fundante y las culturas indígenas: una tesis triunfalista según la cual el cristianismo habría fecundado perfectamente y desde el principio las culturas indígenas; una segunda tesis progresista de la resistencia, en que el Evangelio habría sido un mero instrumento de la dominación e imposición europea, que no consiguió someter la religiosidad ancestral; y una tercera tesis, que denomina del «realismo matizado», que reconoce una población mayoritariamente católica, «como fruto de un lento proceso de evangelización, con fenómenos de sincretismo que fueron, poco a poco, concentrándose en las zonas marginales».

En esta edición de aniversario también presentamos el estudio del historiador brasileño Alexandre Varella, quien ofrece una investigación sobre los problemas culturales relativos a las recetas culinarias con ingredientes americanos escritas por Bernabé Cobo, célebre historiador de la primera mitad del siglo XVII. Sus crónicas, en realidad, trascienden la mera descripción gastronómica para elaborar reflexiones sobre el carácter psicológico y moral de los habitantes del Nuevo Mundo. Varella aborda así problemas históricos derivados de esta particular temática, como el desarrollo de prácticas interculturales en las que el padre jesuita español encuentra — desde la cosmovisión de su tiempo- conexiones, concordancias y observaciones críticas con los hábitos indígenas, mientras advierte sobre 
posibles vicios morales derivados de la falta de temperancia y sobriedad en el consumo de los alimentos del Nuevo Mundo.

Un interesante artículo histórico sobre la articulación económica y cultural hispano-indígena en la segunda mitad del siglo XVI en la región meridional del Colesuyo es presentado por los historiadores chilenos Carlos Choque Mariño y Elías Pizarro Pizarro. El trabajo, que tiene por referencia geográfica el área de Arica y Parinacota en el actual norte de Chile, ofrece «nuevos antecedentes para la comprensión del espacio cultural del Colesuyo, las relaciones económicas y políticas que se desarrollaron a lo largo de este período y su importancia para la construcción de la identidad étnica de la población indígena».

Por su parte, el antropólogo canadiense Nicolas Beauclair expone aquí su propuesta de interpretación eticológica sobre un conocido texto colonial peruano, el Manuscrito de Huarochirí, sobre la base de la validez de estudiar las éticas de los pueblos aborígenes a partir de relatos provenientes de la tradición oral.

Finalmente, tenemos dos trabajos históricos vinculados al bicentenario de la independencia, temática que viene siendo muy apreciada en esta revista. La historiadora española María Saavedra Inaraja presenta un estudio sobre el tratamiento político de los indios por parte de las autoridades vigentes, desde las Cortes de Cádiz hasta el primer Congreso Constituyente del Perú, cuyo desafío común fue cómo incorporar a un Estado liberal a grupos de población con características muy diferentes. Otro académico español, Juan Ignacio Vargas Ezquerra, aborda el complejo tema de la cosmovisión 
intelectual del Perú virreinal previo a la independencia, indagando sobre las ideas en los claustros universitarios de San Marcos en Lima y San Antonio Abad en el Cusco, «en los que tan pronto debatían escolásticos y novatores como se leían clandestinamente obras de L'Encyclopèdie bajo la constante mirada, entre condescendiente y atenta, del virrey del Perú».

Fiel a este espíritu inicial de ensanchamiento del conocimiento de la realidad andina del IPA, la revista ha seguido de algún modo su propio derrotero, afianzándose como una publicación periódica dedicada a los estudios andinos desde diversas ciencias sociales como la Historia, la Sociología o la Antropología. En cuarenta años de existencia, nuestra publicación ha obtenido cierto reconocimiento explícito y también implícito, como se aprecia en el amplio uso académico de sus artículos por parte de autores que, en otras publicaciones, divulgan sus estudios. Tal prestigio no se debe, evidentemente, a nuestra administración, sino a la constante y diligente labor de quienes han estado involucrados en el trabajo editorial de Allpanchis durante estas cuatro décadas. A ellos nuestro reconocimiento y sentido agradecimiento.

Los números hasta ahora editados han procurado mantener la tradición y las peculiaridades de la revista: la temática andina, la interdisciplinariedad, la apertura editorial, la diversidad de autores y el rigor académico de las colaboraciones. En conformidad con las exigencias académicas internacionales vigentes, hemos elaborado una versión actualizada de las normas de autores, un sistema interno de procesamiento de los artículos que implica la revisión de pares de cada trabajo, 
modificaciones de formato según estándares internacionales y la conformación de una nueva estructura del cuerpo editorial. Algunas de estas reformas editoriales están ya presentes en este número y otras se irán incorporando en los números sucesivos, pero todas ellas forman parte de los esfuerzos por cumplir con los estándares internacionales de indización y, por tanto, de garantizar la calidad de los trabajos de investigación originales presentados.

Sean pues estos cuarenta años un aliciente para la labor que como promotores de los estudios andinos desempeñamos en una región que ostenta una riquísima historia y formas culturales complejamente atractivas. Tras cuatro décadas de intensos esfuerzos por fomentar, apoyar y difundir trabajos de investigación, Allpanchis — como señaló alguna vez Javier Iguíniz, entonces director, en el 25..$^{\circ}$ aniversario de la revistahoy «ocupa un lugar destacado en la bibliografía contemporánea sobre el mundo andino y sus protagonistas».

Fernando Valle Rondón 